\title{
A Great Masquerader: Chronic Active Epstein-Barr Virus for the Rheumatologist
}

AMIELEENA CHHABRA, MD, Subspecialty Fellow, Division of Rheumatology, Department of Pediatrics, BC Children Hospital, University of British Columbia; RAIDAN ALYAZIDI, MBBS, MSc, BC Children's Hospital, University of British Columbia, Vancouver, British Columbia, Canada, and Department of Pediatrics, Faculty of Medicine, King Abdulaziz University, Jeddah, Saudi Arabia; ANDREA HUMAN, MD, FRCPC, Clinical Assistant Professor of Pediatrics, Division of Rheumatology, BC Children's Hospital, University of British Columbia, Vancouver, British Columbia, Canada. Address correspondence to Dr. A. Chhabra, Division of Rheumatology, K4-135 Ambulatory building, BC Children's Hospital, 4480 Oak St., Vancouver, British Columbia V6H 3N1, Canada. E-mail: amieleena@yahoo.com. Ethics approval was not required from the institutions' ethics board for this case report. Written and informed consent was obtained from the patient/parent. The authors thank the US National Institutes of Health for their help and support in interpretation of pathology and establishing a diagnosis. J Rheumatol 2019;46:960-1; doi:10.3899/jrheum.180618

Chronic active Epstein-Barr virus (CAEBV) infection is an EBV-associated lymphoproliferative disease defined by (1) illness lasting > 6 months; (2) infiltration of tissues with lymphocytes; (3) elevated EBV DNA, RNA, or proteins in affected tissues; and (4) the absence of any other immunosuppressive condition ${ }^{1,2}$. It has 2 forms: EBV-associated T/natural killer (NK) cell proliferation, and EBV-associated $\mathrm{B}$ cell proliferation ${ }^{3}$. In addition to chronic mononucleosis symptoms, the clinical spectrum includes mucocutaneous disease, uveitis, encephalitis, vasculitis, myocarditis, and hemophagocytosis, thus potentially mimicking rheumatic disease $^{1,2,3,4,5}$

A 9-year-old girl presented with recurrent angioedema and mouth ulcers following 6 months of perioral rash, fevers, night sweats, headaches, and weight loss. Examination revealed periorbital edema, tongue and lip swelling, and diffuse oral mucosal ulceration (Figure 1), tachycardia, hepatomegaly, and bilateral anterior uveitis. Echocardiography revealed coronary aneurysms, but further testing was not suggestive of vasculitis. Infectious investigation revealed high EBV viral load > 58,000 copies/ml peripheral blood, indicating active EBV infection despite serology consistent with past exposure. A mucosal biopsy reviewed by the National Institutes of Health confirmed CAEBV by demonstrating increased EBV-positive cells that were $\mathrm{CD} 3+$ and CD20 - on double-staining, consistent with the T/NK cell subtype.

Given the progressive, life-threatening natural history of CAEBV, the patient underwent a hematopoietic stem cell transplant 7 months following diagnosis. Unfortunately, she died shortly thereafter of posttransplant complications.

CAEBV has multiple manifestations that overlap with

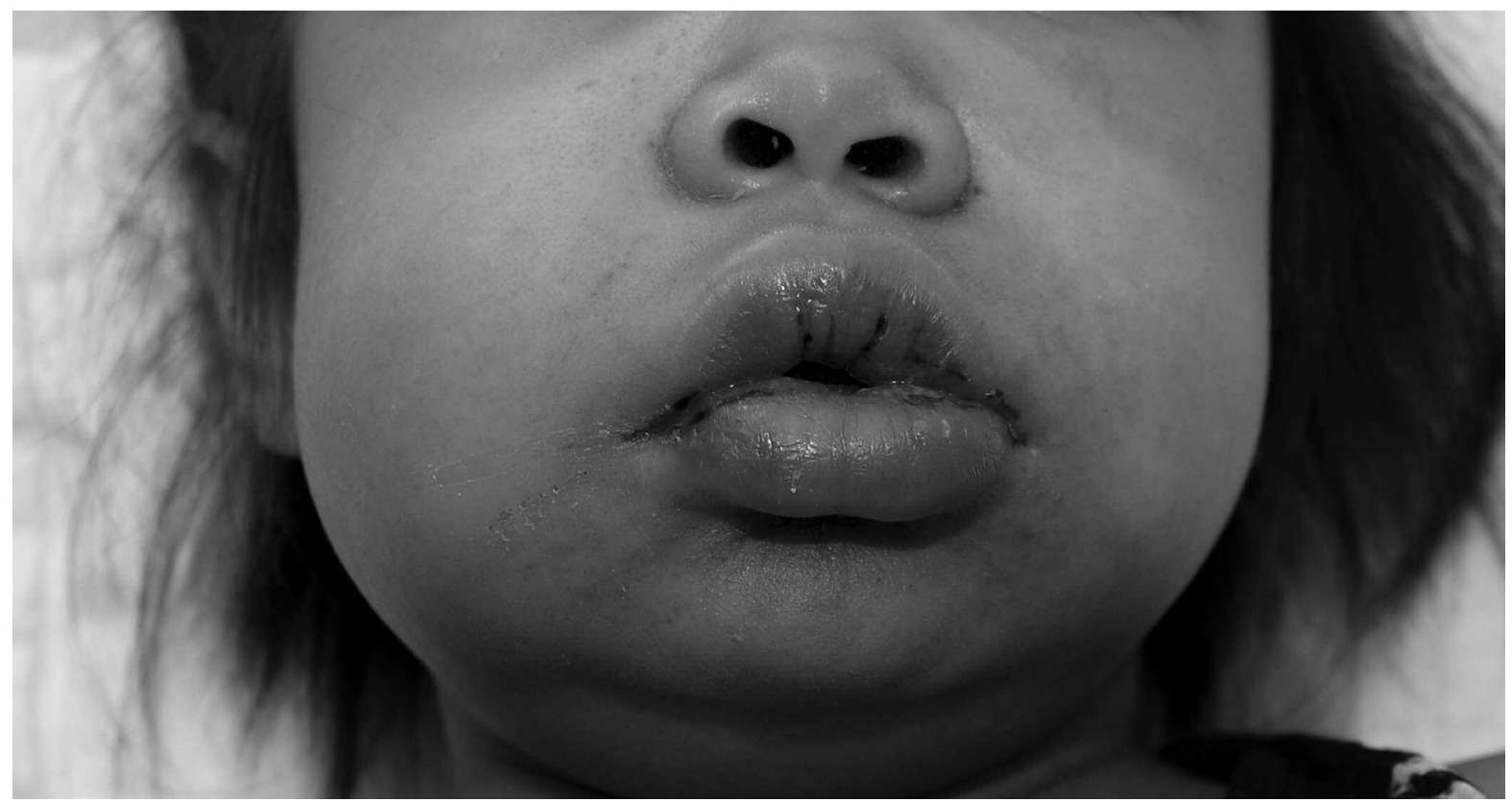

Figure 1. Mucosal irritation and edema.

Personal non-commercial use only. The Journal of Rheumatology Copyright $\odot$ 2019. All rights reserved 
autoimmune and inflammatory conditions, including vasculitis $^{4,5}$. Rheumatologists should consider this rare diagnosis when evaluating patients with complex clinical presentations. CAEBV causing angioedema has not been previously reported.

\section{REFERENCES}

1. Rickinson AB. Chronic, symptomatic Epstein-Barr virus infections. Immunol Today 1986;7:13-4.

2. Cohen JI, Jaffe ES, Dale JK, Pittaluga S, Heslop HE, Rooney CM, et al. Characterization and treatment of chronic active Epstein-Barr virus disease: a 28 -year experience in the United States. Blood 2011;117:5835-49.
3. Cohen JI, Kimura H, Nakamura S, Ko YH, Jaffe ES. Epstein-Barr virus-associated lymphoproliferative disease in non-immunocompromised hosts: a status report and summary of an international meeting, 8-9 September 2008. Ann Oncol 2009;20:1472-82.

4. Kimura H, Cohen JI. Chronic active Epstein-Barr virus disease. Front Immunol 2017;8:1867.

5. Muneuchi J, Ohga S, Ishimura M, Ikeda K, Yamaguchi K, Nomura A, et al. Cardiovascular complications associated with chronic active Epstein-Barr virus infection. Pediatr Cardiol 2009;30:274-81. 